\title{
A CONCEPÇÃO DA VANTAGEM COMPETITIVA POR MEIO DA ANÁLISE DE CUSTOS
}

\author{
THE CONCEPTION OF COMPETITIVE ADVANTAGE THROUGH COST ANALYSIS
}

\author{
André Luiz Pereira de Lima ${ }^{1}$ \\ Taísa Maria Gomes de Lima²
}

RESUMO: Diante de um mundo competitivo em que a economia se torna cada vez mais globalizada e complexa, as organizações se veem cada vez mais preocupadas para continuarem no mercado e fazer a diferença no ramo de atuação. Assim, é de total importância que as organizações controlem os custos de maneira eficaz e eficiente permitindo a realização das atividades diárias, bem como a realização dos compromissos financeiros. Desta forma, as informações vindas da contabilidade de custos passam a ser cada vez mais relevante no processo de tomada de decisão dentro de qualquer organização. No que se refere ao objetivo geral, compreender a importância da análise de custo para a criação de vantagem competitiva nas organizações. Em atendimento aos objetivos específicos, identificar os principais métodos de gestão de custos; identificar quais as práticas utilizadas e benefícios alcançados e destacar o propósito da contabilidade de custos para uma organização. No que concerne os métodos adotados para realização da referida pesquisa foram: a pesquisa bibliográfica, exploratória. Os resultados demostram que na contabilidade de custos, os métodos de custeio são importantes na tomada de decisões, pois a partir disso pode-se determinar o preço de certo produto ou serviço. Tendo em vista isso, para a adoção de um método de custeio segundo Costa (2014), a empresa deve buscar um método que atenda ao máximo os seguintes fatores: controle, competitividade, apropriação, legalidade, gerenciamento, planejamento, supervisão, confiabilidade, precisão e comparabilidade.

Palavras-chave: Empresa. Gestão de Custos. Vantagem competitiva.

ABSTRACT: Faced with a competitive world in which the economy becomes increasingly globalized and complex, organizations are increasingly concerned to remain in the market and make a difference in the industry. Thus, it is of utmost importance that organizations control costs effectively and efficiently, allowing them to carry out daily activities, as well as financial commitments. In this way, information from cost accounting becomes increasingly relevant in the

\footnotetext{
${ }^{1}$ Engenheiro de Produção e pós- graduando em Engenharia de Segurança do Trabalho pela Universidade Estácio de Sá; Bacharel em Engenheiro de Produção - Centro Universitário INTA - UNINTA. Experiência no setor industrial na área de manutenção e Engenharia. E-mail: andrelplimao@gmail.com.

2 Mestranda em Tecnologias Emergentes da Educação pela Must University; Especialista em Gestão de Pessoas (2016) - Universidade Estadual Vale do Acaraú; Bacharel em Administração (2014) - Faculdade Luciano Feijão. Experiência no setor industriário na área de Recursos Humanos, com atuação nos subsistemas de Departamento Pessoal e Desenvolvimento.E-mail: taisagomes@hotmail.com.
} 
decision-making process within any organization. With regard to the general objective, understand the importance of cost analysis to create competitive advantage in organizations. In compliance with specific objectives, identify the main cost management methods; identify the practices used and benefits achieved and highlight the purpose of cost accounting for an organization. Regarding the methods adopted to carry out the referred research were: bibliographic, exploratory research. The results show that in cost accounting, costing methods are important in decision-making, since from this it is possible to determine the price of a certain product or service. In view of this, in order to adopt a costing method according to Costa (2014), the company should seek a method that meets the following factors as much as possible: control, competitiveness, appropriation, legality, management, planning, supervision, reliability, precision and comparability.

Keywords: Company. Costs management. Competitive advantage.

\section{INTRODUÇÃO}

Diante de um mundo competitivo em que a economia se torna cada vez mais globalizada e complexa, as organizações se veem cada vez mais preocupadas para continuarem no mercado e fazer a diferença no ramo de atuação. Cria-se cada vez mais a necessidade de ter uma boa gestão de custos, já que esta é uma das grandes maneiras de encarar os concorrentes, que muitas vezes, estão preocupados apenas em lucrar e não se preocupam com as análises de custos.

Os custos constituem a base dos gastos das empresas e o estudo deles permite que analisemos o cenário de forma realística, mostrando onde está funcionando melhor e onde devem atuar para melhorar e continuar aumentando os lucros. A contabilidade de custos é a parte da contabilidade que se dedica a produzir informações para os vários níveis de uma organização, apoiando as funções de determinação de desempenho, planejamento e controle das operações e na tomada de decisões. O controle de custos coleta, classifica e registra os dados operacionais internos e externos das diferentes atividades da organização. Assim, é de total importância que as organizações controlem os custos de maneira eficaz e eficiente permitindo a realização das atividades diárias, bem como a realização dos compromissos financeiros.

Desta forma, as informações vindas da contabilidade de custos passam a ser cada vez mais relevante no processo de tomada de decisão dentro de qualquer organização. No que se refere à relevância análise de custos, a organização ao adotar um método de custeio para sua gestão, essa funcionará como uma ferramenta que proporcionará ter uma visão mais 
ampla de como acontecem às atividades nos mais diversos setores ou departamentos favorecendo assim um melhor conhecimento dos custos incorridos. Nesse contexto a relevância das empresas adotarem métodos de custeio para tornar a gestão eficaz, é interessante verificar qual o melhor se adapta à organização a fim de que adote um modelo de custeio que apresente melhores resultados para a tomada de decisão.

com base no exposto, o objetivo desta pesquisa se fundamentou em compreender a importância da análise de custo para a criação de vantagem competitiva nas organizações. Os objetivos específicos, identificar os principais métodos de gestão de custos; identificar quais as práticas utilizadas e benefícios alcançados e destacar o propósito da contabilidade de custos para uma organização.

Os métodos adotados para realização da referida pesquisa foram: a pesquisa bibliográfica, exploratória no entendimento de definições e conceitos relacionados a custos, aprofundados de economia, engenharia e do método de custeio baseado em atividades.

Em atenção aos resultados, percebe-se que a contabilidade de custos, os métodos de custeio são importantes na tomada de decisões, pois a partir disso pode-se determinar o preço de certo produto ou serviço. Geralmente, os métodos de custeio mais utilizados são: Custeio baseado em atividades (ABC), custeio por absorção, custeio variável e custeio padrão.

Dessa forma, os métodos de custeio são relevantes nas tomadas de decisões, e para Costa (2014) o período de adoção de um método de custeio é uma fase em que a entidade deverá realizar uma análise detalhada dos objetivos pertinentes à empresa, buscando atender o máximo de necessidades dos diversos setores de forma eficaz e eficiente. Tendo em vista isso, para a adoção de um método de custeio segundo Costa (2014), a empresa deve buscar um método que atenda ao máximo os seguintes fatores: controle, competitividade, apropriação, legalidade, gerenciamento, planejamento, supervisão, confiabilidade, precisão e comparabilidade.

\section{Método de Custeio Baseado em Atividades (ABC)}

Caracteriza-se pela atribuição dos custos indiretos aos produtos através de atividades, ou seja, por meio das tarefas decorrentes da combinação de recursos humanos, financeiros, 
materiais e tecnológicos. Baseia-se no fato que as atividades consomem recursos e os recursos consomem atividades.

Para Bornia (2010) e Ribeiro (2013) o método de custeio ABC é vantajoso pelos seguintes motivos: o rateio é reduzido o que torna as informações gerenciais mais confiáveis, pode ser adaptado em diversos ramos empresariais, identifica rapidamente quais itens estão consumindo mais recursos possibilitando a redução ou eliminação das atividades que não agregam valor. Como desvantagens os autores mencionados citam as seguintes: elevado custo de implantação além da falta de pessoal qualificado para introdução e acompanhamento o que acarretaria uma reorganização de toda a empresa.

\section{Método de Custeio Variável}

Considera como custo de produção apenas os custos variáveis incorridos no processo de produção não avaliando os fixos pelo fato dos mesmos existirem mesmo que não haja produção, considerados assim como despesas. No custeio variável, a diferença entre o valor de vendas líquidas e a soma dos custos variáveis com as despesas variáveis é denominada margem de contribuição, deduzindo da mesma os custos e as despesas fixas obtendo-se o lucro operacional (VICECONTI E NEVES, 2014).

Padoveze (2013) aponta como vantagem do custeio variável a identificação dos produtos mais rentáveis por meio do uso da margem de contribuição, a determinação de valores que a empresa precisa produzir e comercializar para cobrir seus custos e despesas fixas e gerar lucro, as informações de custo, volume e lucro são tempestivas e confiáveis. As desvantagens segundo os autores citados são as seguintes: Não é aceito pela auditoria externa das entidades de capital aberto, nem pela legislação do imposto de renda ferindo alguns princípios contábeis como o da competência e da realização da receita, além disso, a separação dos custos fixos e variáveis não é tão simples como parece, pois também existem os custos de natureza mista, podendo ser alocado de forma errada na separação o que incorreria em problemas para a organização. 


\section{Método de Custeio Padrão}

Caracterizado por ser um custo estimado, ou seja, calculado antes mesmo de iniciado o processo de produção baseado sempre em custos de produção anteriormente realizada. Pode ser dividido em custo real, custo padrão corrente e custo padrão ideal. O custo real é aquele apurado após o processo de produção, fundamentado nos custos efetivos no processo de fabricação. O custo padrão corrente é utilizado com a finalidade de fixação de preço de venda para atender orçamentos visando o fechamento de contratos, nesse caso, o padrão é fixado com base nas produções anteriores tendo a empresa como meta atingi-lo no curto ou longo prazo, visando somente fabricar o necessário acordado com seu cliente. Desta forma percebe- se que o custo real dificilmente coincidira com o padrão corrente ou prefixado.

Como vantagem desse método, Ribeiro (2013) e Costa (2014) destacam o aprimoramento dos controles internos, onde qualquer desvio no processo de produção é facilmente identificado e o gestor pode tomar as providências cabíveis o mais rápido possível, outra vantagem é que esse método serve como ferramenta de avaliação de desempenho, pois os padrões são medidos facilmente saberão quais os níveis que devem ser alcançados quanto à utilização dos materiais e recursos humanos. Já como desvantagem os referidos autores descrevem as constantes correções dos padrões monetários agregados a possíveis dificuldades em determinar os valores desses padrões.

\section{Método de Custeio por Absorção}

$\mathrm{Na}$ visão de Padoveze (2013) nesse método consideram-se todos os custos ou despesas sejam diretos, indiretos, fixos ou variáveis para a apuração do custo unitário dos produtos ou serviços. Apesar de existirem métodos de custeio mais modernos e confiáveis, o custeio por absorção é o mais utilizado no país, pois é aceito pela legislação fiscal, que determina como custos de produção os itens diretos, indiretos, fixos ou variáveis. (BERTI, 2017).

Padoveze (2013) e Berti (2017) mencionam que a principal vantagem do custeio por absorção é que o mesmo atende aos princípios contábeis e são aceitos pela legislação brasileira na preparação das demonstrações contábeis. Já como desvantagens desse método 
na visão dos autores é que o mesmo produz pouca informação gerencial além de dificuldade de definir a base de rateio a ser utilizada

\section{CONCLUSÃO}

Diante do que foi exposto, compreende-se a importância das organizações na gestão da informação para que possam gerar conhecimento e, com isso, criar vantagem competitiva em seu mercado frente aos concorrentes. Os métodos de custeio caracterizam-se como uma ferramenta fundamental dentro de uma organização, responsável pela separação dos custos e despesas, além de contabilizá-los e produzir diversos relatórios que auxiliam nas tomadas de decisão.

\section{REFERENCIAS BIBLIOGRÁFICAS}

BERTI, A. Contabilidade e análise de custos - Teoria e prática. 3. ed. Juruá, 2017.

BORNIA, A. C. Análise Gerencial de custos: aplicação em empresas modernas. 3. ed. São Paulo: Atlas, 20io.

COSTA, W. P. L. B. Fatores influenciadores da adoção de um método de custeio na perspectiva de profissionais em contabilidade com atuação no setor industrial. Dissertação de Mestrado em Administração - Universidade Potiguar, Natal, 2014.

PADOVEZE, C. L. Contabilidade de custos. Teórica. Prática. Integração com Sistemas de Informação (ERP). São Paulo: Cengage Learning, 2013

RIBEIRO, O. M. Contabilidade de Custos. 3. ed. São Paulo: Saraiva, 2013.

SANTOS, E. O. Administração da pequena e média empresa. 2. ed. São Paulo: Atlas, 2010.

VICECONTI, P; NEVES, S. Contabilidade de custos: um enfoque objetivo. II. ed. São Paulo: Saraiva, 2014. 